\title{
Urban MEMS based seismic network for post-earthquakes rapid disaster assessment
}

\author{
A. D’Alessandro ${ }^{1,2}$, D. Luzio ${ }^{2}$, and G. D’Anna ${ }^{1}$ \\ ${ }^{1}$ Istituto Nazionale di Geofisica e Vulcanologia, Centro Nazionale Terremoti, Rome, Italy \\ ${ }^{2}$ Università degli Studi di Palermo, Dipartimento di Scienze della Terra e del Mare, Palermo, Italy \\ Correspondence to: A. D’Alessandro (antonino.dalessandro@ingv.it)
}

Received: 21 May 2014 - Revised: 11 August 2014 - Accepted: 4 September 2014 - Published: 26 September 2014

\begin{abstract}
In this paper, we introduce a project for the realization of the first European real-time urban seismic network based on Micro Electro-Mechanical Systems (MEMS) technology. MEMS accelerometers are a highly enabling technology, and nowadays, the sensitivity and the dynamic range of these sensors are such as to allow the recording of earthquakes of moderate magnitude even at a distance of several tens of kilometers. Moreover, thanks to their low cost and smaller size, MEMS accelerometers can be easily installed in urban areas in order to achieve an urban seismic network constituted by high density of observation points. The network is being implemented in the Acireale Municipality (Sicily, Italy), an area among those with the highest hazard, vulnerability and exposure to the earthquake of the Italian territory. The main objective of the implemented urban network will be to achieve an effective system for post-earthquake rapid disaster assessment. The earthquake recorded, also that with moderate magnitude will be used for the effective seismic microzonation of the area covered by the network. The implemented system will be also used to realize a site-specific earthquakes early warning system.
\end{abstract}

\section{Introduction}

In recent decades, the population growth and the consequent expansion of urban centers, often close to major industrial areas, have led to a significant increase in exposure of the urban areas to the risk induced by earthquakes. When a strong earthquake occurs, the loss of human lives depends primarily on the intensity of the shaking, on the vulnerability of the buildings and on the effectiveness of the rescue operations in the immediate post-quake. The impact of a strong earthquake on an urban center can be considerably reduced by an emergency management center, through timely and targeted actions in the immediate post-earthquake.

A real-time Urban Seismic Network (USN), consisting of a high density of stations installed on the urban center to monitoring, could provide immediate alert and postearthquake information summarized in maps of ground motion parameters, which might allow to greatly improving the effectiveness of rescue operations. The centers for postearthquake emergency management could use this information to decide the action priorities in order to minimize the loss of human lives, with optimally managing the available resources. Unfortunately, the high costs associated with the construction and installation of traditional seismic stations has made impossible (until now) the realization of a seismic network at urban scale.

The recent technological developments in the field of MEMS (Micro Electro-Mechanical Systems) sensors, can now allow the creation of a USN at low cost. MEMS device are a highly enabling technology with a huge commercial potential. In the 90s, MEMS sensors revolutionized the automotive airbag system and are today widely used in laptops, games controllers and mobile phones. Thanks to the great commercial success, the research and development of MEMS technology actively continues all over the world.

Due to their versatility, MEMS sensors are increasingly being used in a wide field of science, including the physical, engineering and medical one. In the last decade, a number of research institutes in the fields of geophysics and seismology gained interest in this promising technology. Nowadays, the sensitivity and the dynamic range of these sensors are such as to allow the recording of earthquakes of moderate magnitude even at a distance of several tens of kilometers (D'Alessandro 
and D'Anna, 2013; Evans et al., 2014). Moreover, because of their low cost and small size, MEMS accelerometers can be easily installed in urban areas in order to achieve an USN constituted by very densely spaced stations. In California the development of seismic networks consisting of MEMS sensors has already started, including the Quake-Catcher Network (Cochran et al., 2009), operated by Stanford University, and the Community Seismic Network (Clayton et al., 2011) operated by the California Institute of Technology. However, the aforementioned networks are still at an experimental stage as they are built on the basis of the activities of volunteers. It is clear however, that the international community of seismology is focusing on that technology that could revolutionize in a short time the way to monitor earthquakes (Chung et al., 2011; Cochran et al., 2012; Kohler et al., 2013; Lawrence et al., 2014; D'Alessandro, 2014b).

At the beginning of 2014, under an agreement between the University of Palermo, the National Institute of Geophysics and Volcanology and the Department of Sicilian Civil Protection (Italy) has been funded a project called MEMS (Monitoring of Earthquakes through MEMS Sensors). The MEMS project involves the realization of an USN constituted of stations based on MEMS technology. As a pilot site for the realization of the MEMS project was chosen the municipality of Acireale (Sicily, Italy), whose urban areas are among those with the highest seismic hazard and vulnerability to the earthquake effects in Italy (Azzaro et al., 2010, 2013).

The network that is being achieved will be able to measure both the translational and the rotational component of the wave field generated by an earthquake. The MEMS stations will be located inside strategic and sensitive buildings (i.e. characterized by high vulnerability and exposure) such as schools, hospitals, public buildings and places of worship. The recorded waveforms will be processes in real-time by an automated system to determine, following a moderate to strong earthquake, several shaking parameters that will be used to create shake maps at the urban scale. These maps can be used by the competent authorities, like the Civil Protection, for the optimization of the immediate post-quake interventions.

In the following, after the characterization of Acireale in terms of historical seismicity and related seismic hazard, we describe as we are realizing the USN and the postearthquakes rapid disaster assessment system. Both performances, potentialities and possible future developments will be discussed.

\section{Acireale setting}

The area selected for the realization of the USN is the Acireale municipality (Italy). Acireale is located in the middle of the Ionian coast of the Sicily, at the southeastern slopes of the Etna volcano (Fig. 1). The municipality covers an area of about $40 \mathrm{~km}^{2}$ with a population in excess of 50000 (population density of 1300 inhabitants per $\mathrm{km}^{2}$ ). The city settled in the current area as early as the fourteenth century. The town is sited on a lava plateau called Timpa, with an average altitude of about $160 \mathrm{~m}$.

The urban plan is typical of late-medieval cities of Sicily. Acireale is regarded as an important economic, cultural and artistic heritage. The center of Acireale has many historic buildings and places of worship of great artistic value, which are considered to be sites of national heritage. The National Institute for Conservation and Restoration has identified more than a hundred of historic buildings of great cultural and artistic value having high seismic vulnerability. Acireale, which has grown considerably in the second half of the nineteenth century as the "City of the Studies", now gathers a large number of primary, secondary and higher secondary, public and private schools, used by most students of neighboring municipalities. Figure 2 shows the location of more than 200 sites with high exposure and vulnerability to the earthquake identified among the historic buildings and schools of the Acireale municipality.

The town of Acireale is exposed to the effects of damage of both regional earthquakes and local volcano-tectonic events (Fig. 1). Among the first one there are several strong earthquakes such as those of 1169 and 1693, located in the southeastern Iblean, and that of 1908, with epicenter in the Strait of Messina. The earthquake of 4 February 1169, hit the entire eastern Sicily and the southern part of Calabria causing major destruction. This earthquake shook all the villages that arose in the current area of Acireale. The earthquake of 1169 caused the almost total destruction of the villages and the dispersion of the population in the hinterland with the birth of the various Aci villages. In 1693, on two occasions, on 9 and 11 January, two earthquakes hit a vast area of eastern Sicily hard. The effects were catastrophic in about 40 towns in the Noto Valley. The damage caused by the two earthquakes were enormous, since it can be considered the greatest catastrophe in the history of the Italian seismicity. Acireale was devastated; more than sixty per cent of its built heritage was destroyed. There were 739 victims on a population of nearly 13000 inhabitants. The earthquake of 28 December 1908, had its epicenter in the Messina Straits and caused very serious damages and collapses in all towns that stood on the northern and eastern slopes of Mount Etna, also taking several deaths in Acireale.

To such catastrophic events, also some destructive local earthquakes must be added, as that of $1818(M=6.2)$ and the numerous volcano-tectonic events generated by the Etna volcano. Even if such events have generally low magnitude $(M<5)$, because of its shallow depth $(<2 \mathrm{~km})$, in the past have caused very serious damage and even destruction with maximum epicentral intensity of $X$ of the European Macroseismic Scale (EMS-98, Grünthal, 1998).

Figure 1a shows the distribution of earthquakes that occurred in the Etna region from 1669 to 2008. In less than 200 years over 190 earthquakes occurred that 
(a)

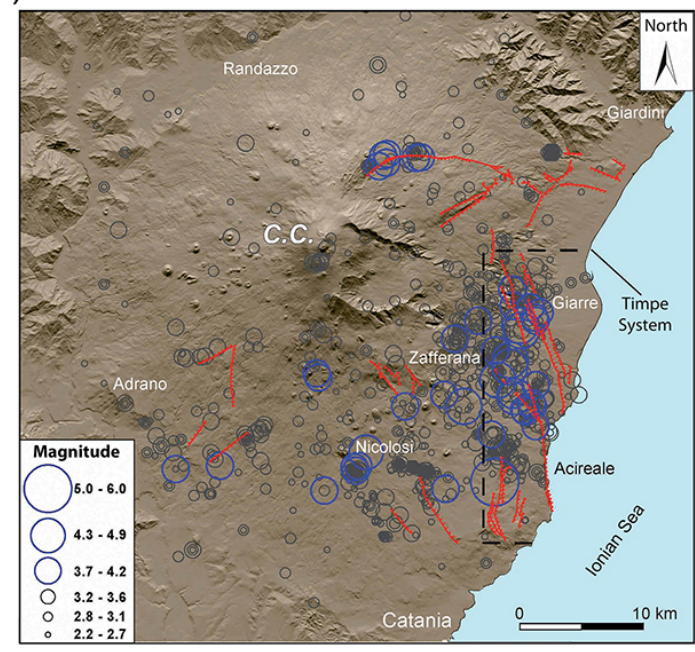

(b)

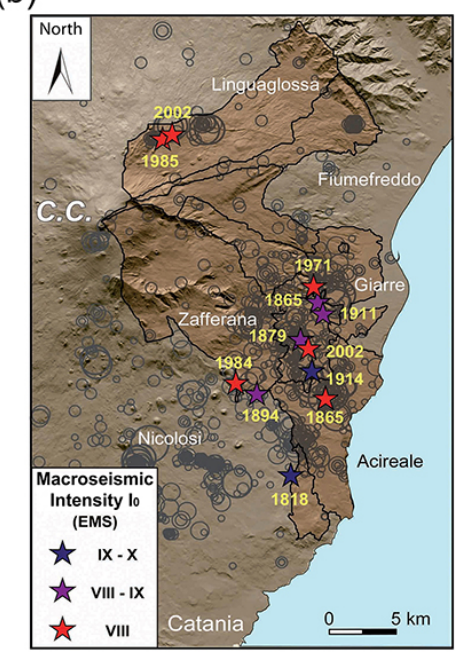

Figure 1. (a) Distribution of Etna earthquakes occurred between 1669 and 2008 (Azzaro et al., 2010). In blue the epicenters of earthquakes of magnitude $M \geq 3.7$, corresponding to an epicentral intensity $I_{0} \geq$ VII EMS, in gray smaller events $\left(I_{0} \leq\right.$ VII EMS). The red lines indicate major faults outcropping (dashes on the low side); (b) earthquakes with epicentral intensity $I_{0} \geq$ VIII EMS-98, corresponding to a magnitude $M \geq 4$.1, occurred from 1669 to 2008 in the Acireale and surrounding areas (Azzaro et al., 2010).

caused damage, almost one every year. These earthquakes have caused severe damage $\left(I_{0}=\right.$ VII-VIII EMS-98) every 15 years and destruction $\left(I_{0}=\right.$ IX-X EMS-98) with loss of human lives every 30 years (Azzaro et al., 2010). Figure $1 \mathrm{~b}$ instead shows the earthquakes with epicentral intensity $I_{0} \geq$ VIII EMS-98, corresponding to magnitudes $M \geq$ 4.1, occurred from 1669 to 2008 in the Acireale and surrounding areas (Azzaro et al., 2010). Most of these events were generated by the Timpe fault system on which stands the Acireale town. This system is characterized by a set of tectonic structures with complex failure mechanisms, strongly heterogeneous from the point of view of seismotectonic behavior.

In recent times, several neighborhoods of the Acireale town were damaged by the mainshock $\left(M_{L} 4.4\right)$ of the seismic sequence that started on 29 October 2002. Following this earthquake, more than 400 buildings of Acireale were declared uninhabitable.

Recent seismic microzonation studies (Azzaro et al., 2010) have highlighted the extreme variability of the Acireale substrate foundation (Fig. 2). This shows a great lithological variability, showing rapid lateral and vertical variations from over-consolidated clays, to massive lava, slag or anthropogenic carryovers. The strong geological variations have made the characterization of Acireale in seismic perspective very difficult and the seismic microzonation unsatisfactory. These abrupt changes of the geology (in particular the presence of low $S$ wave velocity body in contact with a high $S$ wave velocity body) may generate strong site effects that can significantly amplify the intensity of shaking during an earthquake. Current and recent floods in contact with old rocks are present in the Acireale urban area (Fig. 2). A detailed microzonation of the urban center of Acireale, based on direct observation of the shaking caused by an earthquake, would therefore be highly desirable, especially looking at the results of recent studies of seismic hazard of the eastern slope of the Etna (Azzaro et al., 2013).

\section{Instruments, methods and performance}

MEMS devices have been recognized as one of the most promising technologies of the XXI century, able to revolutionize both the industrial world and that of the consumer products. MEMS devices have dimensions on the order of microns and are made directly on a silicon substrate. The construction technique is fairly simple and therefore economical, because is the same of any integrated circuit (photolithographic process). The electromechanical microsystems are nothing more than a set of devices of various kinds (mechanical, electrical and electronic) highly miniaturized integrated on the same silicon substrate, combining electrical properties of the semiconductor integrated with the opto-mechanical one. Therefore, these "intelligent" systems combine electronic and mechanical functions in a very small space.

The operation of MEMS can be described considering the integrated circuit as the "brain" of the system that makes possible the monitoring of the surrounding environment through the other devices (sensors) found on the same chip. A MEMS device is therefore a system capable of receiving information from the environment by translating the physical quantities into electrical impulses. The sensors can measure phenomena of various kinds: mechanical (sound, acceleration 


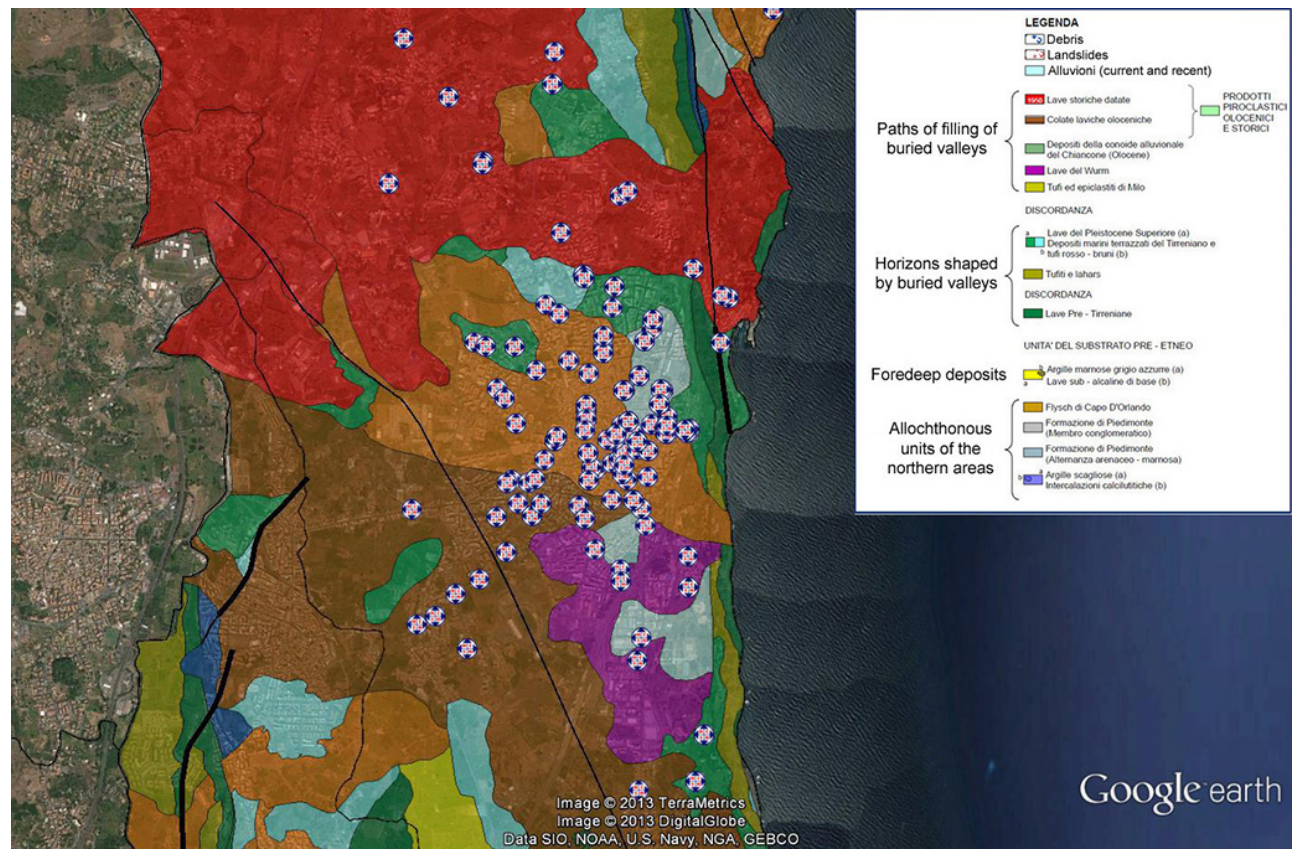

Figure 2. Geological map of Acireale and surrounding (Azzaro et al., 2010) with located more than 200 candidate sites identified among historical buildings and schools with high seismic vulnerability and exposure.

and pressure), thermal (temperature and heat flux), biological (cell potential), chemical $(\mathrm{pH})$, optical (intensity of light radiation, spectroscopy), magnetic (intensity of flow).

Nowadays, the sensitivity and the dynamic range of several low-cost MEMS accelerometers are such as to allow the recording of earthquakes of moderate magnitude even at a distance of several tens of kilometers (D'Alessandro and D'Anna, 2013; Evans et al., 2014). The MEMS device used for the construction of the stations that will constitute the USN, is the model 1044_0 (3/3/3 PhidgetSpatial Precision High Resolution) produced by the Canadian company Phidget Inc. The sensor was chosen from among hundreds of MEMS devices on the market based on its performance, cost and in relation to the objectives that the MEMS project aims to achieve.

The MEMS device model 1044_0 (Fig. 3) integrates a three-axis capacitive accelerometer and is also equipped with a gyroscope and a magnetometer, both tri-axial. The circuit of transduction is internal to the device and is of the digital type, for which the outputs are already in a digital format and proportional to the measured quantity. The integrated accelerometer is able to measure both constant accelerations (usable as a tilt sensor) or variable in time (used to measure the oscillation induced by an earthquake). It features three sensing elements oriented along three mutually orthogonal axes able to measure the acceleration vector of the wavefield generated by an earthquake. All accelerometers manufactured by Phidgets are individually calibrated by absolute measurements of gravity along the three axes, and this guarantees the high accuracy of the sensors. The recent paper
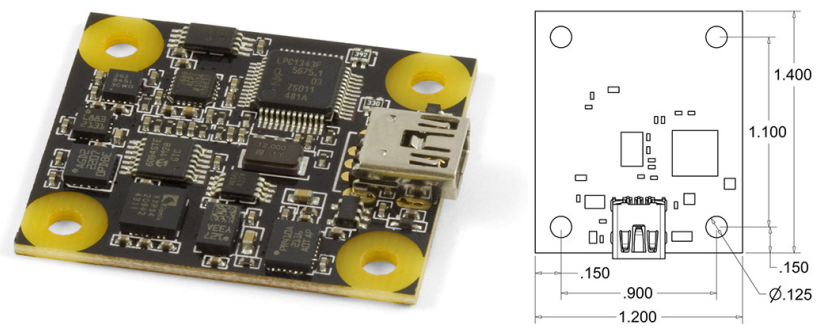

Figure 3. MEMS model 1044_0 (3/3/3 PhidgetSpatial Precision High Resolution) produced by the Canadian company Phidget Inc.; the reported measures are in inches.

published by Evans et al. (2014) and further laboratory tests, confirms the high performance of this MEMS accelerometer and its suitability for the earthquakes monitoring.

The integrated accelerometer operates in high sensitivity mode for acceleration less of $\pm 2 \mathrm{~g}\left(\mathrm{~g}=9.80665 \mathrm{~m} \mathrm{~s}^{-2}\right)$; in this range, the sensor provides a linear output signal. This value guarantees that the sensor is able to record even very strong accelerations, such as those induced by a catastrophic earthquake, remaining in linear regime. The resolution or sensitivity of the sensor is $76.3 \mu \mathrm{g}$, which implies a dynamic range greater than $44 \mathrm{~dB}$. The bandwidth, which is the frequency band in which the system has linear response, is $0-497 \mathrm{~Hz}$. As well known the frequencies generated by an earthquake are at most of the order of tens of Hz. Those of interest for earthquake engineering, i.e. those that can create more damage to buildings triggering resonance 
phenomena, are included in a more narrow range (approximately $0.1-20 \mathrm{~Hz}$ ) and therefore largely contained in the frequency band of this MEMS accelerometer. The MEMS accelerometer self-noise has standard deviation of $280 \mu \mathrm{g}$. It is clear that any seismic acceleration less than this value would be hardly detectable in the signals acquired by the sensor. However, this value of standard deviation does not constitute a limitative factor for the aim of the MEMS project because is of the same order of that expected for the seismic noise in urban areas.

In order to evaluate the performance of the USN in terms of detection magnitude, was determined the Power Spectrum Density (PSD) of the self-noise generated by the tri-axial accelerometer integrated into the MEMS device model 1044_0. The self-noise noise was determined by acquiring $72 \mathrm{~h}$ of signal, using six MEMS 1044_0 devices, at a site characterized by very low seismic noise. The acceleration PSD's calculated for all three components of the six sensors are very similar; therefore their average value has been calculated (Fig. 4a). In the frequency range $0.05-40 \mathrm{~Hz}$, the PSD lies between approximately -58 and $-70 \mathrm{~dB}\left(\mathrm{~m} \mathrm{~s}^{-2}\right)^{2} \mathrm{~Hz}^{-1}$ and shows a monotonically decreasing trend as a function of frequency. For a comparison, in Fig. 4a is also shown the upper Peterson (1993) seismic noise reference PSD. This PSD indicates the maximum expected power for the seismic noise of sites where the bedrock outcrop, located far from urban center or industrial areas, and refers only to the vertical component. The self-noise produced by the MEMS sensor is quite a bit higher than the Peterson (1993) reference curve, but low enough to allow recording of earthquakes of moderate magnitude, and therefore suitable for the purposes of the project.

Moreover, as well known, human and industrial activities generate an intense noise in a wide range of frequencies, which can exceed of $20-30 \mathrm{~dB}$ the upper Peterson (1993) curve. In addition, the ambient noise recorded on the horizontal components, is generally much larger than that recorded on the vertical component, in particular in the presence of site effects. For the aims of the MEMS project, the stations will be installed in the urban center, sampling all outcropping lithologies. For these reasons, would be useless to use accelerometers with better performance but much more expensive. Figure $4 \mathrm{~b}$ shows a local earthquake of $M_{L} 4$ recorded by a MEMS 1044_0 devices and by a professional force balance accelerometer at the epicentral distance of about $35 \mathrm{~km}$; the PSD of this earthquake is reported in Fig. 4a. It is possible to observe that, in a relative wide range of frequencies, the spectrum of the earthquake exceeds in power that of the self-noise of the MEMS accelerometer.

In order to evaluate the performance of such MEMS sensor in detecting the PGA on the horizontal components generated by an earthquake, we used the empirical attenuation law obtained by Ambraseys et al. (1996) and Simpson (1996). This attenuation law has been obtained from the analysis of 422 European earthquakes with hypocentral depth less than $30 \mathrm{~km}$, magnitude between 4 and 7.9 and epicentral distance
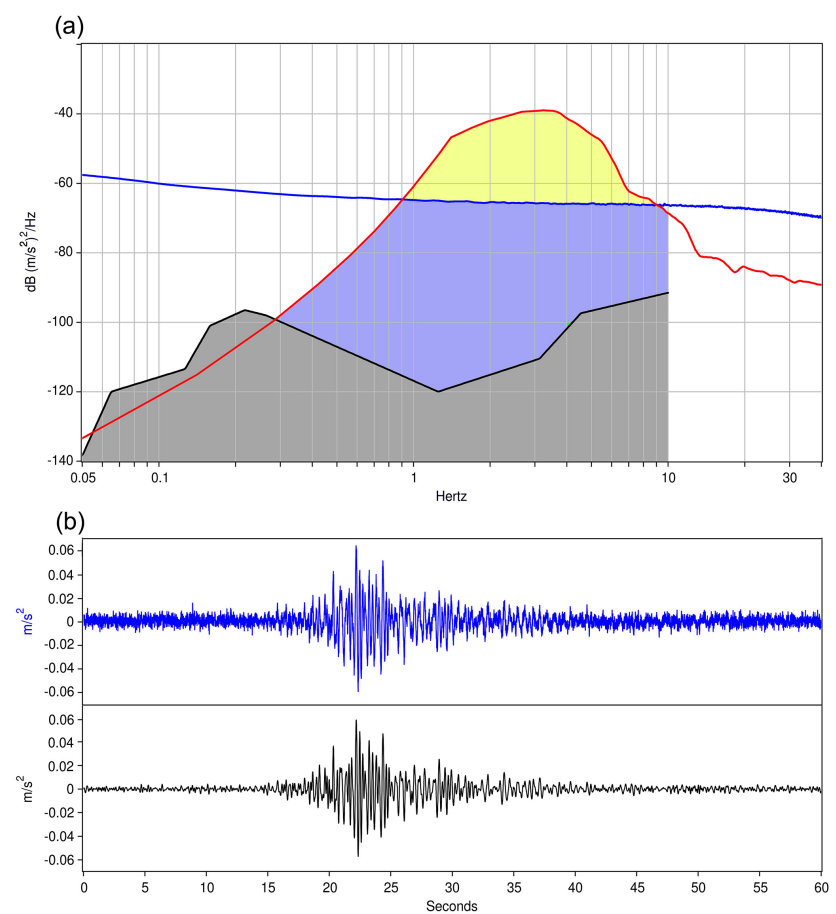

Figure 4. (a) Average PSD of the self-noise produced by the MEMS 1044_0 device accelerometer (blue line) with over plotted the mean horizontal earthquake spectra (red line) of a shallow local seismic event with $M_{L} 4$ recorded at the epicentral distance of about $35 \mathrm{~km}$ by the same device. For comparison it is also over plotted the upper Peterson (1993) seismic noise reference PSD (black line); (b) raw NS component waveform of the local event described in (a) as recorded by a MEMS 1044_0 device accelerometer (blue line) and a professional force balance accelerometer (black line).

between 0 and $260 \mathrm{~km}$. Using this empirical law we determined the PGA values (horizontal components) generated by earthquakes of magnitude $\left(M_{S}\right)$ between 3 and 7.8 and epicentral distance between 0 and $300 \mathrm{~km}$. These PGA values were compared with the values of standard deviation of the self-noise of the tri-axial accelerometer integrated in the MEMS device model 1044_0. Figure 5 shows the values of magnitude and hypocentral distance for which the MEMS accelerometer would be able to record the PGA of the horizontal components, with a signal to noise ratio greater than 10. The figure shows how the PGA generated by events of magnitude 3 may be recorded up to hypocentral distances of about $70 \mathrm{~km}$, in the case of bedrock outcrops, and of about $130 \mathrm{~km}$, in the case of soft soil. The PGA generated by earthquakes of greater magnitude can be clearly recorded also at hypocentral distances significantly higher.

In addition, the Single Board Computer (SBC) used for the realization of the station (described follow) has various digital inputs that may allow the addition of other MEMS sensors. Adding additional MEMS accelerometers to a single station could improve the signal to noise ratio by means of the synchronously stacking of the signals. Assuming that 


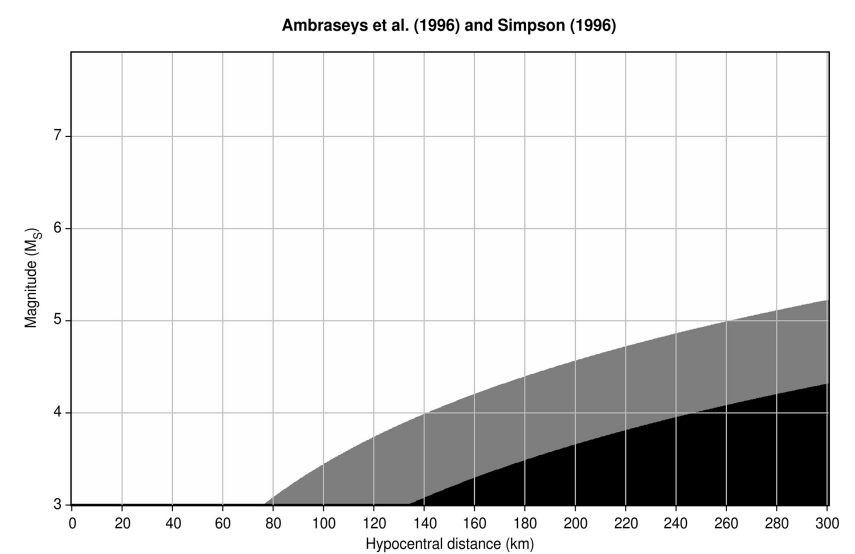

Figure 5. The graph shows, as a function of the magnitude $\left(M_{S}\right)$ and of the hypocentral distance, the detection performance of the accelerometer integrated into MEMS device model 1044_0. The chart was obtained comparing the values of standard deviation of the noise self-produced by the MEMS sensor with the PGA values, expected on the horizontal components, determined by the empirical law of Ambraseys et al. (1996) and Simpson (1996). The white and gray areas are those where the expected PGA exceeds the standard deviation of the MEMS accelerometer self-noise by a factor of 10 , for sites with soft sediments and bedrock outcrops, respectively.

the coherent signal (in our case the earthquake waveform) is the same in the $N$ recordings, while the self-noise is not correlated, the synchronously stacking of the signals would allow an increase in the signal to noise ratio equal to $\sqrt{ } N$.

However, a tri-axial accelerometer alone does not allow the full characterization of the ground motion generated by an earthquake. The motion of the medium sampled by the wavefield generated by an earthquake can be described splitting the wave field into two parts: translational and rotational. Because of the difficulties associated with the realization of highly sensitive instruments capable of measuring with accuracy and precision the rotational motion generated by an earthquake, the modern seismology is based on the measurement of the translational component only. However, numerous scientific papers report observations of rotational motions generated by earthquakes (Lee et al., 2009a, b). In the last decade a new field of seismology has developed, called Rotational Seismology, which studies all the aspects related to rotation motions that can be induced by earthquakes. The two recent monographs Teisseyre et al. $(2006,2008)$ and an entire special issue devoted to this topic by the Seismological Society of America (Lee et al., 2009a) confirm the importance of this rapidly developing branch of seismology. Therefore, the complete characterization of the ground shaking caused by an earthquake should include both translational and rotational measures.

As previously stated, the MEMS device model 1044_0 also includes a tri-axial gyroscope, which is an instrument capable of measuring the angular velocities of all three axes (the same of the accelerometer). In precision mode, the gyroscope seems to have good performance (resolution of 0.02 and $0.013^{\circ} \mathrm{s}^{-1}$ on horizontals and vertical axis, respectively, self-noise standard deviation of $0.095^{\circ} \mathrm{s}^{-1}$, and maximum measurable speed $>300^{\circ} \mathrm{s}^{-1}$ ). Unfortunately, since the still small number of experimental observations made in the field of Rotational Seismology, it is not possible to estimate the maximum possible rotations expected due to an earthquake and therefore determine the effectiveness of this sensor for the monitoring of earthquakes.

The MEMS device has a low power consumption, estimated at a maximum current consumption of $55 \mathrm{~mA}$. Power can be supplied via a simple USB connection with a potential difference of between 4.4 and $5.3 \mathrm{~V}$. The sampling step can be set between a minimum of $4 \mathrm{~ms}$ to a maximum of $1 \mathrm{~s}$, in local acquisition mode, and in a minimum of $12 \mathrm{~ms}$ for a maximum of $1 \mathrm{~s}$, in remote acquisition mode. These sampling steps, according to the Nyquist theorem, allow reconstruction without aliasing of frequencies up to 125 and $41 \mathrm{~Hz}$ in local or remote mode, respectively. These values ensure the possibility to properly observe all frequencies of interest in the field of earthquake seismology. The analog to digital conversion is done automatically by means of a 16-bit digital converter. Furthermore, the temperature range of operation is extremely large $\left(-40\right.$ to $85^{\circ} \mathrm{C}$ ) ensuring the operation of the device even in the most extreme temperature conditions. All specifications above described, together with the small size of the device $(3 \times 3.5 \times 0.4 \mathrm{~cm})$ and its low cost, make this MEMS device suitable for the implementation of the USN.

Another sensor included in the MEMS device is the triaxial magnetometer. This magnetometer can be used as an electronic compass facilitating, during the installation of a station, the correct orientation of the horizontal components with respect to the North. Such information, together with the values of the acceleration of gravity, allow the correct installation of the MEMS station without any external reference. In addition, once station is installed it is possible to remotely control any changes in these parameters caused by accidental movement of the device.

For the realization of the MEMS stations we also used the SBC 1073_0 even produced by the Phidgets Inc (Fig. 6). The SBC handles the pre-processing of the acquired signals and their routing and forwarding, via TCP/IP, to a server properly laid out for the collection and analysis of data recorded by all stations that will constitute the USN. The SBC is provided with a network adapter with an Ethernet port and WiFi antenna for the connection to the network. In addition to the MEMS device described above, the SBC manages the data acquired from a GPS antenna, necessary for the time synchronization of the acquired signals. The SBC is provided with several input and output ports that can easily allow the integration of other sensors in a technological upgrade.

An appropriately sized buffer battery, capable of powering the station in case of electrical blackout, accompany the described system. All the elements described so far, are integral part of the seismic station and included in an appropriate 

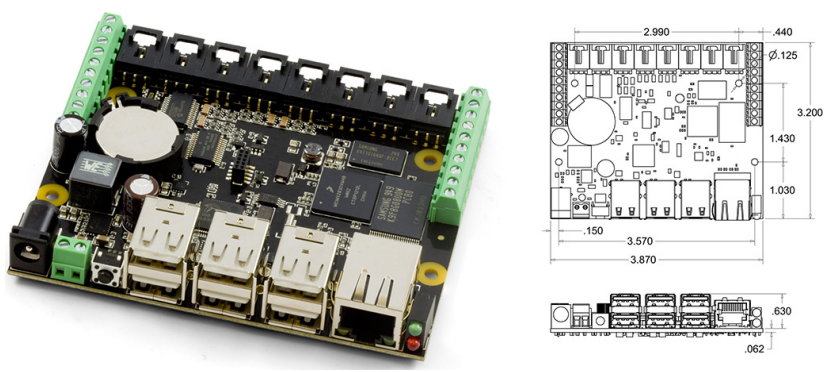

Figure 6. SBC model 1073_0 produced by the Canadian company Phidget Inc.; measurements are in inches.

case that protects the electro-mechanical devices from strong shocks or the presence of water.

The total cost of realization of a MEMS station is estimated to be less of EUR 600. This cost is much lower therefore that of a standard strong motion station and allows the realization of a high density of stations USN at very low costs.

Suitable sites will be sought between the strategic and sensitive buildings (i.e. those with high exposure and vulnerability to earthquake), such as schools, hospitals, public buildings and places of worship, already highlighted for the Acireale urban center in Fig. 2. Additional sites will also be identified and evaluated during the project. Station will be located among them, within the same buildings or in areas close to these locations. During the identification of the suitable sites for installation of the MEMS stations, we will assess the structural nature of the building and the ability to access the foundation plans. For each building, we will carefully evaluate possible soil-structure interaction and the stations will be installed at the foundation of structures. The final geometry of the network will provide the most comprehensive and homogeneous coverage of the urban area, taking into account the local geological conditions and the values of exposure and vulnerability of the identified sites.

The data acquired by the MEMS network will be sent in real time to a Server that will handle their collection and processing. The system will be built according to the traditional Client-Server scheme (Fig. 7); the individual MEMS stations will be the Clients while a properly sized computer, will act as a Server. The signals will be transmitted using the TCPIP Internet Protocol. The Server will be installed at the INGV seismic room, where specialized staff, present $24 \mathrm{~h}$ on 24 and 7 days a week, can monitor the operation of the system.

The server will process the signals transmitted by different stations in order to extract the different parameters that can be used to assess the potential damage due to of an earthquake. The potential damage will be estimated by an automatic system, appropriately implemented, that will determine some parameters, such as the maximum of the PGA and the Arias (1970) intensity of an earthquake, measured by each station of the network. These parameters will be used to

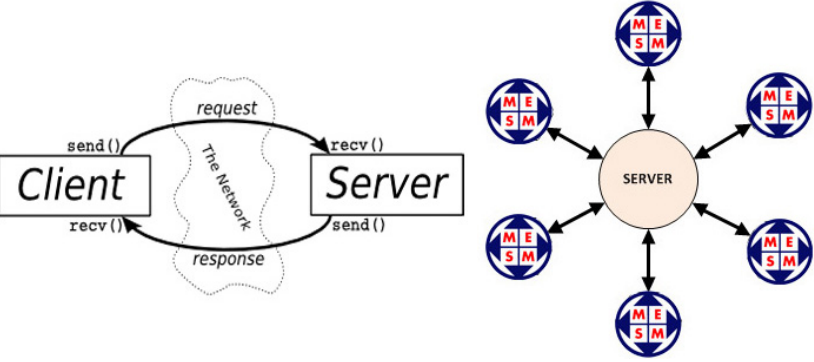

Figure 7. Schematic example of the client-server system that will be implemented under the MEMS project.

construct, in almost real-time, shake maps for the area covered by the network. Suitable algorithms will be developed for avoiding false alarms that may be generated during anthropogenic transients generated in proximity of one or more MEMS station. The implemented algorithms will allow the creation of a shake map only if a significant percentage of the MEMS stations simultaneously detect an event. In case an earthquake is established, the server will send the information and the shake maps produced to the competent authorities for the actions in the immediate post-earthquake, such as Civil Protection.

\section{Conclusion and general remarks}

The realization of the USN would have a high socioeconomic impact, providing a useful tool to reduce the seismic risk, capable of increasing the safety of the population of the urban area covered by the network. The impact of a strong seismic event on an urban community can be reduced with a well-planned and timely action by the centers for the emergency management. The MEMS project will lead to the realization, in the Acireale Municipality, of the first real-time USN for the post-earthquakes rapid disaster assessment. It would be an important tool for civil protection authorities by providing timely alerts that allow a rapid and effective mobilization of the post-earthquake interventions. The implemented system will be able to timely provide the distribution of the intensity of the ground shaking due to an earthquake. The shaking maps would allow the involve centers, the optimal management of priorities and the allocation of resources so as to achieve a significant reduction in the number of victims following an earthquake. The rescue operations and verification of damage to buildings could then be carried out according to a logic of priority on the basis of the highest urban shaking measured by the seismic network. It would minimize secondary effects induced by an earthquake allowing the protection of critical infrastructure and may allow the economic and social structures to return to the "normal" as quickly as possible.

The MEMS project would lead to the realization of the first network able to record both translation and rotational 
component generated by a strong earthquake, leading to enormous advances in the field of Rotational Seismology. The data collected could be used for the accurate reconstruction of the seismogenic processes and seismogenetic structures that generated the earthquakes recorded. This would lead to enormous advances in the understanding of the earthquake generation phenomena.

The data acquired, also after a low magnitude earthquake, will provide important information for seismic microzonation of the Acireale Municipality. From Fig. 2 we can see that the candidate sites are located on lithologies with very different mechanical behavior that may generate strong site effects. The use of direct measurements of ground motion generated by an earthquake could help to significantly improve the Acireale seismic microzonation and critically evaluate the results of the previous investigations obtained by empirical or indirect methods. This could possibly lead to the development and validation of new techniques and new approaches to the assessment of the site effects.

The project would lead to the development of innovative algorithms for real-time analysis of accelerometric signals and for the construction of shake maps at urban scale. Great progress could be made in the field of the Earthquake Early Warning System (EEWS). The extreme characteristics of the ground motion generated by a strong earthquake could be estimated in the first few seconds of the initial $P$ wave allow realizing a site-specific EEWS. This EEWS could be usable to enhance in real-time the safety margin of specific critical engineered systems mitigating the seismic risk by reducing the exposure of the facility by automated safety actions.

The prototypes of seismic stations, designed and built with the latest MEMS technology, will lead the acquisition of an important technological know-how. This know-how could be used to improve the performance of existing seismic networks (D'Alessandro et al., 2011a, b, 2012b, 2013a, c; D'Alessandro and Stickney, 2012; D'Alessandro and Ruppert, 2012) or for the realization of highly miniaturized sensors usable in extreme environmental conditions, like in volcanic areas (D'Alessandro et al., 2013d) or in ocean bottoms (D'Alessandro et al., 2009, 2012a, 2013b; Mangano et al., 2011; D'Alessandro, 2014a). Such knowledge could be also used for the further development of MEMS stations suitable to monitor also other environmental parameters of great scientific interest. The implemented system could revolutionize the way to monitor earthquakes and quickly be extended to all areas with high seismic risk in Italy and other countries.

Acknowledgements. We are grateful to the anonymous reviewers, to Elizabeth Cochran and the Editor Damiano Pesaresi for their constructive comments and suggestions. We want to thank Giuseppe Chiarenza, Calogero Foti and the Dipartimento Regionale della Protezione Civile (Sicily), for the technical and logistical support. Special thanks to Chester Fitchett and the Phidgets Inc. (Canada) without which this project would not have been achieved.

\section{References}

Ambraseys, N. N., Simpson, K. A., and Bommer, J. J.: Prediction of horizontal response spectra in Europe, Earthq. Eng. Struct. D., 25, 371-400, 1996.

Arias, A.: A measure of earthquake intensity, in: Seismic design of nuclear power plants, The MIT Press, 438-468, 1970.

Azzaro, R., Carocci, C. F., Maugeri, M., and Torrisi, A.: Microzonazione sismica del versante orientale dell'Etna, Studi di primo livello, Regione Siciliana, Dipartimento della Protezione Civile, Le Nove Muse Editrice, 184 pp., 2010.

Azzaro, R., D’Amico, S., Peruzza, L., and Tuvè, T.: Probabilistic seismic hazard at Mt. Etna (Italy): The contribution of local fault activity in mid-term assessment, J. Volcanol. Geoth. Res., 251, 158-169, doi:10.1016/j.jvolgeores.2012.06.005, 2013.

Chung, A. I., Neighbors, C., Belmonte, A., Miller, M., Sepulveda, H. H., Christensen, C., Jakka, R. S., Cochran, E. S., and Lawrence, J. F.: The Quake-Catcher Network Rapid Aftershock Mobilization Program Following the 2010 M 8.8 Maule, Chile Earthquake, Seismol. Res. Lett., 82, 526-532, doi:10.1785/gssrl.82.4.526, 2011.

Clayton, R. W., Heaton, T., Chandy, M., Krause, A., Kohler, M., Bunn, J., Guy, R., Olson, M., Faulkner, M., Cheng, M., Strand, L., Chandy, R., Obenshain, D., Liu, A., and Aivazis, M.: Community Seismic Network, Ann. Geophys.-Italy, 54, 6, doi:10.4401/ag-5269, 2011.

Cochran, E. S., Lawrence, J. F., Christensen, C., and Jakka, R. S.: The Quake-Catcher Network: Citizen Science Expanding Seismic Horizons, Seismol. Res. Lett., 80, 26-30, doi:10.1785/gssrl.80.1.26, 2009.

Cochran, E. S., Lawrence, J. F., Kaiser, A., Fry, B., Chung, A., and Christensen, C.: Comparison between low-cost and traditional MEMS accelerometers: a case study from the M7.1 Darfield, New Zealand, aftershock deployment, Ann. Geophys.-Italy, 54, 728-737, doi:10.4401/ag-5268, 2012.

D'Alessandro, A.: The Marsili Seamount, the biggest European volcano, could be still active!, Curr. Sci., 106, p. 1339, 2014a.

D'Alessandro, A.: Monitoring of earthquakes using MEMS sensors, Curr. Sci., 107, 733-734, 2014b.

D'Alessandro, A. and D'Anna, G.: Suitability of low cost 3 axes MEMS accelerometer in strong motion seismology: tests on the LIS331DLH (iPhone) accelerometer, B. Seismol. Soc. Am., 103, 2906-2913, doi:10.1785/0120120287, 2013.

D'Alessandro, A. and Ruppert, N.: Evaluation of Location Performance and Magnitude of Completeness of Alaska Regional Seismic Network by SNES Method, B. Seismol. Soc. Am., 102, 2098-2115, doi:10.1785/0120110199, 2012.

D’Alessandro, A. and Stickney, M.: Montana Seismic Network Performance: an evaluation through the SNES method, B. Seismol. Soc. Am., 102, 73-87, doi:10.1785/0120100234, 2012.

D'Alessandro, A., D'Anna, G., Luzio, D., and Mangano, G.: The INGV's new OBS/H: analysis of the signals recorded at the Marsili submarine volcano, J. Volcanol. Geoth. Res., 183, 17-29, doi:10.1016/j.jvolgeores.2009.02.008, 2009.

D’Alessandro, A., Luzio, D., D’Anna, G., and Mangano, G.: Seismic Network Evaluation through Simulation: An Application to the Italian National Seismic Network, B. Seismol. Soc. Am., 101, 1213-1232, doi:10.1785/0120100066, 2011a.

D’Alessandro, A., Papanastassiou, D., and Baskoutas, I.: Hellenic Unified Seismological Network: an evaluation of its perfor- 
mance through SNES method, Geophys. J. Int., 185, 1417-1430, doi:10.1111/j.1365-246X.2011.05018.x, 2011b.

D’Alessandro, A., Mangano, G., and D'Anna, G.: Evidence of persistent seismo-volcanic activity at Marsili seamount, Ann. Geophys.-Italy, Scientific News, 55, 213-214, doi:10.4401/ag5515, 2012a.

D'Alessandro, A., Danet, A., and Grecu, B.: Location Performance and Detection Magnitude Threshold of the Romanian National Seismic Network, Pure Appl. Geophys., 169, 2149-2164, doi:10.1007/s00024-012-0475-7, 2012b.

D'Alessandro, A., Gervasi, A., and Guerra, I.: Evolution and strengthening of the Calabrian Regional Seismic Network, Adv. Geosci., 36, 11-16, doi:10.5194/adgeo-36-11-2013, 2013a.

D'Alessandro, A., Mangano, G., D'Anna, G., and Luzio, D.: Waveforms clustering and single-station location of microearthquake multiplets recorded in the northern Sicilian offshore region, Geophys. J. Int., 194, 1789-1809, doi:10.1093/gji/ggt192, 2013b.

D’Alessandro, A., Badal, J., D’Anna, G., Papanastassiou, D., Baskoutas, I., and Özel, M. M.: Location Performance and Detection Threshold of the Spanish National Seismic Network, Pure Appl. Geophys., 170, 1859-1880, doi:10.1007/s00024-0120625-y, 2013c.

D’Alessandro, A., Scarfi, L., Scaltrito, A., Di Prima, S., and Rapisarda, S.: Planning the improvement of a seismic network for monitoring active volcanic areas: the experience on Mt. Etna, Adv. Geosci., 36, 39-47, doi:10.5194/adgeo-36-39-2013, $2013 \mathrm{~d}$.

Evans, J. R., Allen, R. M., Chung, A. I., Cochran, E. S., Guy, R., Hellweg, M., and Lawrence, J. F.: Performance of Several Low-Cost Accelerometers, Seismol. Res. Lett., 85, 147-158, doi:10.1785/0220130091, 2014.

Grünthal, G.: European Macroseismc Scale 1998 (EMS-98), European Seismological Commission, subcommission on Engineering Seismology, working Groupo Macroseismic Scales, Conseil de l'Europe, Cahiers du Centre Euroéen de Géodynamique et de Séismologie, 15, Luxembourg, 99 pp., 1998.

Kohler, M. D., Heaton, T. H., and Cheng, M.-H.: The community seismic network and quake-catcher network: enabling structural health monitoring through instrumentation by community participants, Proc. SPIE 8692, Sensors and Smart Structures Technologies for Civil, Mechanical, and Aerospace Systems 2013, 86923X (19 April 2013), doi:10.1117/12.2010306, 2013.
Lawrence, J. F., Cochran, E. S., Chung, A., Kaiser, A., Christensen, C. M., Allen, R., Baker, J. W., Fry, B., Heaton, T., Kilb, D., Kohler, M. D., and Taufer, M.: Rapid Earthquake Characterization Using MEMS Accelerometers and Volunteer Hosts Following the M 7.2 Darfield, New Zealand, Earthquake, B. Seismol. Soc. A., 104, 184-192, 2014.

Lee, W. H. K., Celebi, M., Todorovska, M. I., and Igel, H.: Introduction to the special issue on rotational seismology and engineering applications, B. Seismol. Soc. Am., 99, 945-957, 2009a.

Lee, W. H. K., Igel, H., and Trifunac, M. D.: Recent Advances in Rotational Seismology, Seismol. Res. Lett., 80, 479-490, doi:10.1785/gssrl.80.3.479, 2009b.

Mangano, G., D’Alessandro, A., and D’Anna, G.: Long-term underwater monitoring of seismic areas: design of an Ocean Bottom Seismometer with Hydrophone and its performance evaluation, OCEANS 2011 IEEE Conference, 6-9 June, Santander, Spain, in OCEANS 2011 IEEE Conference Proceeding, 9 pp. doi:10.1109/Oceans-Spain.2011.6003609, 2011.

Peterson, J.: Observation and modelling of background seismic noise, U.S. Geol. Surv. Open-File Rept., Albuquerque, New Mexico, 93-322, 1993.

Simpson, K. A.: Attenuation of strong ground-motion incorporating near-surface foundation conditions, Ph.D. thesis, University of London, 1996.

Teisseyre, R., Takeo, M., and Majewski, E. (Eds.): Earthquake Source Asymmetry, Structural Media and Rotation Effects, Berlin: Springer, 2006.

Teisseyre, R., Nagahama, H., and Majewski, E. (Eds.): Physics of Asymmetric Continua: Extreme and Fracture Processes: Earthquake Rotation and Soliton Waves, Berlin \& Heidelberg: Springer-Verlag, 2008. 